\title{
PRAGMATISMO E EPISTEMOLOGIA: A PERSPECTIVA NATURALISTA-INSTRUMENTALISTA DE DEWEY
}

\author{
Pragmatism and epistemology: the naturalist-instrumentalist perspective of Dewey
}

\author{
Darcísio Natal Muraro \\ UEL
}

\begin{abstract}
Resumo: O presente artigo tem por objetivo analisar o problema epistemológico na obra de Dewey. Abordaremos a crítica aos pressupostos da epistemologia tradicional e sua tentativa de reconstruir uma posição distinta por meio da lógica da investigaçăo. O estudo de caráter fillosófico, qualitativo na análise de conceito envolvendo o campo do conhecimento, mostra que este pensador tomou posição crítica diante do que chamou de epistemologia, termo que designa o conjunto de filosofias construídas sobre dualismos como sujeito e objeto, teoria e prática, mente e corpo, espírito e matéria. Tais dualismos surgem da divisão social de classes e servem para a sustentação delas, impedindo a liberdade de criação e comunicação da experiência. Contrapondo-se a este entendimento de epistemologia, Dewey argumenta pela necessidade da lógica como investigação da investigação, ou conhecimento do conhecimento. A contribuição da lógica fillosófica da investigação, sua versão da epistemologia, é a de analisar os processos de investigação para abstrair as leis da experiência reflexiva e reorientar o trabalho da filosofia em todas as áreas, inclusive nessa mesma, a lógica. Dewey depreende uma lógica da investigação como processo voltado para a continuidade da vida. O pensamento parte de uma situação indeterminada e culmina na transformação dessa situação por meio de etapas intermediárias de observação, reflexão e ação inteligentemente orientada. A lógica da investigaçăo tem por base a matriz biológica-cultural. Assim, Dewey desenvolve a lógica da experiência que atinge as mais diversas dimensões como a moral, a política e a educação.
\end{abstract}

Palavras chaves: Epistemologia. Lógica. Experiência. Dewey. Naturalismo. Instrumentalismo.

\begin{abstract}
The present article aims to analyze the epistemological problem in Dewey 's work. We will approach criticism of the assumptions of traditional epistemology and its attempt to reconstruct a distinct position through the logic of inquiry. The study of a philosophical, qualitative character in the analysis of concept involving the field of knowledge, shows that this thinker took a critical position before what he called epistemology, a term that designates the set of philosophies built on dualisms as subject and object, theory and practice, mind and body, spirit and matter. Such dualisms arise from the social division of class and serve to sustain it, preventing the freedom of creation and communication of experience. Opposing this understanding of epistemology, Dewey argues for the necessity of logic as investigation of inquiry, or knowledge of knowledge. The contribution of the philosophical logic of research, its version of epistemology, is to analyze the processes of investigation to abstract the laws of reflexive experience and reorient the work of philosophy in all areas, including logic itself. Dewey understands a logic of inquiry as a process for the continuity of life. The thought starts from an indeterminate situation and culminates in the transformation of this situation through intermediary stages of observation, reflection and action intelligently oriented. The logic of research is based on the biological-cultural matrix. Thus, Dewey develops the logic of experience that reaches into the most diverse dimensions such as morality, politics and education.
\end{abstract}

Keywords: Epistemology. Logic. Experience. Dewey. Naturalism. Instrumentalism.

O presente trabalho tem por objetivo discutir o problema filosófico do significado de epistemologia no pensamento de John Dewey. A compreensão do posicionamento de Dewey sobre a epistemologia somente pode ser feita por meio da análise das bases da filosofia deste pensador e sua relação com a história da filosofia. 
Para iniciar a reflexão acerca desta problemática e nos situar no campo conceitual propomos trabalhar com a seguinte questão: o que epistemologia?

O estudo etimológico da palavra epistemologia nos diz que ela é composta pelas palavras episteme, que em grego quer dizer ciência e logos que quer dizer discurso, estudo, teoria. Historicamente a palavra apareceu no vocabulário filosófico a partir de meados do século XIX, na abordagem do Positivismo de Augusto Comte, que atribuiu às ciências a tarefa de estudar a realidade e produzir o conhecimento e a filosofia, como epistemologia, a função de analisar os procedimentos, metodologias e resultados da ciência.

Como filósofo dedicado ao estudo da epistemologia, o brasileiro Hilton Japiassu (1992, p. 25, itálicos do autor) diz que a tarefa deste ramo da filosofia "[...] é o estudo crítico dos princípios, das hipóteses e dos resultados das diversas ciências. Semelhante estudo tem por objetivo determinar a origem lógica (não psicológica) das ciências, seu valor e seu alcance objetivo". Neste caso, a tarefa da epistemologia é da crítica do conhecimento buscando analisar seu valor e o seu alcance lógico, social, político. A análise da origem lógica do conhecimento põe para o epistemólogo o seguinte trabalho:

[...] estudar a gênese e a estrutura dos conhecimentos científicos. Mais precisamente, o de tentar pesquisair as leis reais de produção desses conhecimentos. E ela procura estudar esta produção dos conhecimentos, tanto do ponto de vista lógico, quanto do ponto de vista linguísticos, sociológicos, ideológicos, lógico, etc. (JAPIASSU, 1992, p. 38-39).

Na perspectiva de Japiassu, a epistemologia não é um trabalho solitário no campo filosófico, mas dialoga com outras áreas como a ética, lógica, política, bem como com outras disciplinas como a sociologia, a linguística.

No dicionário filosófico de Runes, encontramos a seguinte definição de epistemologia: "O ramo da filosofia que investiga a origem, estrutura, métodos e validade do conhecimento". Nesta mesma fonte encontramos uma diferenciação entre lógica e epistemologia: "[...] lógica é a ciência formal dos princípios que governam o raciocínio válido; epistemologia é a ciência filosófica da natureza do conhecimento e da verdade."

Considerando este entendimento de epistemologia como "teoria do conhecimento" ou "análise filosófica da natureza do conhecimento e da verdade" ou "estudo da gênese e a estrutura dos conhecimentos científicos", e, ainda mais precisamente, uma compreensão critico-histórico-social do conhecimento, podemos trabalhar com a hipótese de que Dewey tem uma epistemologia e esta ocupa um lugar central em sua filosofia. Entretanto, ao analisar a posição do autor sobre a epistemologia encontraremos uma posição bastante crítica acerca deste termo e de suas pretensões no campo filosofia.

A epistemologia vem se desenvolvendo como um campo um campo de saber filosófico assinalado por diferentes perspectivas na análise da atividade filosóficocientífica. Podemos destacar algumas destas perspectivas epistemológicas, por vezes conflitantes entre si, e exatamente por este motivo de fundo filosófico são de grande relevância para pensar o problema do conhecimento: a epistemologia genética de J. Piaget, a epistemologia histórica de G. Bachelard, a epistemologia racionalista-crítica de K. Popper, a epistemologia arqueológica de M. Foucault. Nosso objetivo neste estudo não é analisar estes enfoques epistemológicos, nem um estudo comparativo deles com a perspectiva do pragmatismo. O termo pragmatismo foi usado para chamar a filosofia norte-americana em desenvolvimento no final do século XIX e inń́cio do século XX, vindo a se firmar como uma vertente filosófica com diferentes matizes, mas que buscam pensar a experiência como objeto central da filosofia diferenciando-se do racionalismo e do idealismo. Esta perspectiva filosófica se contrapõe aos estilos de pensamento, de ordem religiosa ou não, os quais buscam seus fundamentos no absoluto ou num modelo de razão que determina a priori a possibilidade do conlhecimento e, neste sentido, e busca instaurar uma nova e distinta forma de pensar experimentalmente. 
No vasto campo da filosofia pragmatista, nosso recorte busca analisar mais detalhadamente a perspectiva de John Dewey. Neste sentido, a epistemologia de Dewey pode ser designada como pragmatismo naturalista ou instrumentalista. O próprio autor denominou sua filosofia como naturalismo empírico ou empirismo naturalista, humanismo naturalista, além de instrumentalismo.

É no conjunto da obra deweyana que fica mais clara a posição do autor sobre a epistemologia. Ratner, um estudioso da filosofia de Dewey, nos dá uuma visão da amplitude do Pragmatismo deweyano identificando três círculos concêntricos e integrados:

A primeira área, em direção ao círculo interno, é ocupada pelo pensamento reflexivo, pela lógica, ou o que Dewey chama de investigação. Na segunda área estão os modos típicos da experiência humana, tais como o prático e o vitilitárío, a estética, a religião, ético-social, científico. A terceira área é aquela do mundo sócio-cultural, a sociedade nas suas formas organizadas e institucionais, o mundo que gera o que nós simplesmente e bastante corretamente chamamos de 'questões sociais'. (RATNER, 1939, p. 49-50, aspas do autor)

Podemos dizer que este primeiro círculo ligado ao pensamento reflexivo, à lógica ou investigação é basilar na filosofia deweyana, permitindo ao autor expandir suas ideias para os outros campos, mantendo coerência com os princípios ali traçados. Um destes princípios é o que caracteriza sua filosofia como naturalismo.

Dewey prefere o termo naturalismo porque permite um posicionamento claro diante das diversas maneiras de conceber o mundo no campo filosófico. Primeiro, o termo designa uma oposição ao idealismo ou super-naturalismo que apela para princípios transcendentais a priori colocados sobre a natureza e em afastamento do papel da experiência para o conhecimento. Em segundo lugar, o naturalismo permite aliar a filosofia à ciência como forma de combater os estilos de pensamento de ordem religiosa ou não, os quais buscam seus fundamentos no absoluto ou num modelo de razão que determina a priori a possibilidade do conhecimento. Terceiro, o naturalismo difere de materialismo, mesmo quando este defende a experiência dependente das condições físicas existenciais em suas funções como condição para todas as formas especiais de atividades e valores sócio-bióticos. Neste sentido, a não aceitação do materialismo resulta da não aceitação da teoria metafísica da sulbstância. Ele evita o materialismo porque este entende, na filosofia, a matéria em oposição ao psíquico e o mental como espiritual. Quando se abandona essa posição antitética, perde-se o sentido de materialismo ou matéria. Além disso, o autor aponta uma indefinição do que é o materialismo / matéria diante da impossibilidade de generalizar para a filosofia o sentido deste termo quando tomado das ciências físicas (expresso em símbolos matemáticos) e que distingue do que se define como energia.

O intento de Dewey é tomar posição crítica em relação às filosofias metafísicas e, assim, romper com as teses dualistas ontológicas, porque elas pressupõem a existência de uma "realidade" superior à precariedade e contingência da vida. Opõe-se às filosofias que se colocam a buscar certezas absolutas e propõe a filosofia experimental que se guia pela contínua investigação a partir da experiência existencial.

Dewey toma como pressuposto do naturalismo a mudança ininterrupta - o continuum de incerteza e indeterminação - do mundo como fonte para o desenvolvimento de qualquer tipo de conhecimento. Com este ponto de partida, sua filosofia busca operar a síntese entre os dualismos: eu-mundo, alma-corpo, Deusnatureza, inteligência e ação, inteligência e emoção, teoria e prática, saber e fazer, espírito e corpo, trabalho e lazer. A tradição filosófica ocidental privilegiou o primeiro termo destes dualismos e criou um abismo intransponível entre eles. Por consequência, estes dualismos sustentam a divisão social das classes doutas e classes trabalhadoras, ricos e pobres, nos que mandam e nos que são mandados. Eles representam as rupturas 
sociais de continuidade entre os diversos grupos sociais e legitimam a rigidez da dessa divisão de classes.

Neste sentido a crítica aos dualismos é a crítica à cultura dualista que permeia todos os âmbitos da vida ou, mais especificamente, uma forma de crítica à filosofia tradicional como mantenedora das classes:

A fillosofia tradicional está respaldada pela persistência de condições sociais das quais surgiu originariamente a fórmula do dualismo entre teoria e prática, a saber, a hierarquia familiar que vem das atividades servis e mecânicas às liberais, livres e socialmente estimadas. (DEWEY, 1960, p. 76-77)

Dewey usa o termo epistemologia para se referir a estas teorias filosóficas do conhecimento criticadas pelo dualismo inerente em contraposição aos pressupostos do naturalismo. Este se pauta pelo princípio de continuidade e interação entre os pares antitéticos do dualismo em que há isolamento dos pares conhecer e fazer, teoria e prática, mente e corpo, eu e mundo, sujeito e objeto, atividades servis e mecânicas e atividades livres e estimadas etc. A perspectiva dualista leva Dewey a criticar a epistemologia porque este campo pressupõe a separação sujeito e objeto para dar legitimidade aos conhecimentos:

Este isolamento se espelhou no grande desenvolvimento do ramo da filosofia conhecido pelo nome de epistemologia - a teoria do conhecimento. A identificação do espírito com o eu, e a apresentação do eu como uma coisa independente e que se basta a si mesma, criou tão grande abismo entre o espírito ou o conhecedor, e o mundo, ou o conhecido, que suirgiu a questão de sabei-se como era possível qualquer espécie de conhecimento. Dado um sujeito - o conhecedor, - e um objeto - a coisa a ser conhecida, totalmente separados um do outro, era necessária arquitetar-se uma teoria para explicar como podiam entrar em mútuas relações, de modo a tornar-se possível um legítimo conhecimento. (DEWEY, 1979, p. 323)

Dewey desenvolveu sua crítica mostrando a insustentabilidade dessas concepções dualistas e buscou explicitar o processo do conhecimento, pautando-se pelos princípios de continuidade e interação.

As diferentes filosofias dualistas adotam uma premissa comum: a negação do caráter de contingência do universo. A própria origem destas filosofias se encontra nessa mescla da estabilidade e segurança. Assim, estas filosofias ficam circunscritas a um âmbito doméstico e de domínio, ao conceber o mundo da existência real com o caráter de completo, acabado e seguro.

Dewey considera que existem duas maneiras de compreender como ocorre o processo de produção do conhecimento na natureza e na cultura: a epistemológica, que se pauta pelo método dedutivo, e a lógica, que se guia pelo método experimental ou indutivo. Nesta versão de epistemologia, segundo o entendimento deweyano, o conhecimento tem significado em si mesmo, independente da conexão com a inquirição, uma vez que resulta do trabalho de um espírito isolado que contempla a verdade como sendo fixa e imutável.

A identificação do espírito com o eu individual e deste último com uma consciência psíquica particular, relativamente moderna. Tanto na Grécia como nos tempos medievais a regra era considerar-se o indivíduo como um instrumento por cujo intermédio se manifestava uima inteligência divina e universal. O indivíduo não era propriamente o "conhecedor", o agente do conhecimento; este era a "Razão", que se manifestava por meio dele. (DEWEY, 1979, p. 321-322)

Os conhecimentos que se produzem por esta via podem desenvolver duas formas distintas de comportamento na sociedade: o dogmatismo ou o individualismo. 0 
primeiro transforma o cabedal de significações produzidas pela razão em dogmas gerando uma sociedade governada pelo costume que cercea e reprime "[...] toda a concepção das coisas diferentes da autorizada pela crença corrente [...]" (DEWEY, 1979, p. 326). Em continuidade a essa citação, Dewey é enfático em criticar a censura social que torna fatal o desenvolvimento das novas idéias, alijando os que se aventuram nesse caminho ou simplesmente negando os recursos requeridos para o adequado desenvolvimento das mesmas. A segunda, a atitude individualista, toma como pressuposto da origem e desenvolvimento do conhecimento a interioridade do indivíduo, ignorando e negando os vínculos sociais da mesma vida mental. Diz o autor:

Implanta-se o individualismo moral com a separação consciente de diferentes centros da vida. Elle tem suas raízes na noção de que a consciência de cada pessoa é totalmente particular, é um continente fechado em si mesmo, intrinsecamente independente das idéias, desejos e propósitos de qualquer outra pessoa. (DEWEY, 1979, p. 328)

Segundo o autor estas duas situações subentendem o indivíduo como um contemplador passivo diante das verdades. Dewey critica essa interpretação pela contradição intrínseca na medida em que apela para a razão para a produção do conhecimento, mas, ao mesmo tempo, quer tutelar a própria razão pela autoridade. Ela produz o isolamento do indivíduo do mundo e dos outros, facilitando o desenvolvimento de uma autoridade externa de controle pautada na crença de posse da verdade absoluta. Assim, subsiste uma ruptura de continuidade nas relações entre indivíduo e sociedade. Contrapondo-se a esta visão, Dewey entende que o agir humano se faz sempre num mundo público e comum. Por isso, coloca como base de todo o conhecimento a constituição social do eu:

O fato é que todo o indivíduo se desenvolveu e sempre deverá desenvolver-se em um meio social. Suas "respostas" tornam-se inteligentes ou adquirem significação simplesmente porque ele vive e age em um meio de significações e valores reconhecidos como tais. Pelo intercâmbio social, tomando parte em atividades que encarnam convicções, ele gradualmente adquire espírito próprio. A concepção de espírito como uma coisa isolada que o indivíduo possui está polarmente oposta à verdade. O indivíduo cria o espírito, desenvolve a mente na proporção em que o conhecimento das coísas se acha corporificado na vida que o cerca; o eu não é um espírito isolado a criar novos conhecimentos por sua conta própria. (DEWE', 1979, p. 325)

Para este autor, o papel do indivíduo ou do eu no processo do conhecimento exige uma condição social para "[...] atitude de revisão crítica das crenças antigas" e progresso dos conhecimentos que pressupõe o intercâmbio social. Historicamente esse processo é resultado da luta pela liberdade de pensamento: "A liberdade de observação e de imaginação subentendida na moderna revolução científica não foi facilmente assegurada; foram precisas lutas para consegui-la; muitas pessoas sofreram por sua independência intelectual." (DEWEY, 1979, p. 327). A história da humanidade gira em torno da luta pelo domínio do pólo do dualismo que sustenta o poder. A revolução copernicana iniciou com o desenvolvimento das ciências, mais especificamente com o traballho de Galileo, Newton e demais pensadores que se aplicaram em desenvolver o método experimental lançando bases para o desenvolvimento das ciências modernas.

A crítica deweyana ressalta esta relação do conhecimento com a cristalização da sociedade em costumes fixos e a negação da revisão destes conhecimentos:

[...] mas uma sociedade governada pelo costume não encoraja seu desenvolvimento. Pelo contrário - tende a reprimi-las, por se desviarem das idéias dominantes. Em comunidade dessa espécie, torna-se suspeito o homem que encare as coisas diferentemente dos outros; persistir, para ele, será geralmente fatal. Mesmo quando não é tão rigorosa a censura social das 
opiniōes, as condições sociais podem deixar de proporcionar os recuirsos requeridos pelas novas idéias para o seu adequado desenvolvimento; ou poderão deixar de dar apoio e recompensa materiais aos que as houverem concedido. Daí - permanecerem como simples fantasias, românticos castelos de ar, ou especulações sem objetivos. (DEWE'Y, 1979, p. 327)

Em contraposição a esta rigidez do comportamento fixado em conhecimentos como certezas inabaláveis, o autor propõe uma atitude investigadora em que o pensamento exerça a função de indagar e reconstruir as crenças:

Mas tudo o que se admite sein se pôr em đúvida, tudo o que se considera verdade assente em nossas mútuas relações e em nossas relações com a natureza, é o que, em dado tempo, chamamos conhecimento. Ao invés disso, o ato de pensar começa, conforme vimos, pela dúvida ou incerteza. Elle representa uma atitude indagadora, buscadora, investigadora, em vez de o ser de domínio e posse. Mediante seu processo crítico o verdadeiro pensamento é revisto e ampliado, e são reorganizadas nossas convicções sobre determinados estados de coisas. (DEWEY, 1979, p. 326)

Dewey se propõe a reconstruir a filosofia a partir do método experimental, método que une teoria e prática na investigação dos problemas em todas as esferas da vida ou da experiência: psicológica, educacional, política, lógica, ética-moral, estética e os que a evolução der origem. Fazer a crítica do pressuposto do dualismo leva assumir a contingência do universo. Para ele, reconhecer a existência, ambiente onde nasce a cultura, gira em torno de um fato relevante que é a natureza instável e insegura do mundo: "[...] a evidência de que o mundo das coisas empíricas inclui o incerto, imprevisível, incontrolável e perigoso." (DEWEY, 1958, p. 42) Em continuidade o autor explicita detalhadamente a característica marcante que preside todos os objetos da experiência: o contraste. Diz o autor:

O visível está assentado no invisível; e, no fim, o que é não visto decide o que acontece no que se vê. O que é tangível descansa de forma precária sobre o que não é tocado nem agarrado. O contraste e o mal ajustamento potencial do imediato, a óbvia e focal fase das coisas, com estes fatores indiretos e ocultos que determinam a origem e o curso do que está presente, são fatores indestrutíveis de todas e de cada uma de nossas experiências. Podemos qualificar de supersticiosa a forma de fazer frente ao contraste de nossos antepassados, porém o contraste mesmo não é superstição. É um dado primário de toda experiência." (DEWEY, 1958, p. 43-44)

O mundo natural não é aquele de necessidades mecânicas fechadas. O mundo natural é aquele marcado pelas contingências que dá lugar a potencialidades ainda não manifestadas. Neste sentido, podemos entender que a natureza é a experiência em seu curso em que a capacidade de pensar torna possível a mudança reconstruindo a própria natureza, inclusive do sujeito pensante.

Continua o argumento do autor:

Nem o eu nem o mundo, nem a alma nem a natureza (no sentido de algo isolado e acabado em seu isolamento) constituem o centro, como tampouco a Terra e o Sol constituem o centro de um sistema universal e necessário de coordenadas. Temos uim todo movente de partes interatuantes, suirge um centro ali, onde surge um esforço para mudá-las em uma direção particular" (DEWEY, 1960, p. 55, grifos nossos).

O naturalismo assume a condição primária da natureza: ela é constituída por um complexo movimento imprevisível e incompleto, ela é mudança, acontecimento de mútua interação ou transação. Nos termos usados por Dewey: 
Todo acontecimento passa enquanto tal a ser outras coisas, de tal maneira que o que ocorre posteriormente é uma parte integrante do caráter ou natureza da existência presente. Üma 'coisa' (affair), res, está sempre en questão, mesmo que se trate de uma mudança química, da aparição da vida, da linguagem, do espírito, ou dos episódios que compõem a história humana. Cada um vem de outro e cada um, quando vem tem suas próprias qualidades imediatas iniciais imprevisíveis e suas próprias qualidades terminais similares. O posterior não se resolve nunca integralmente no anterior. O que chamamos como resolução é meramente uma reformulação de ordem, por meio da qual regulamos o passo do anterior ao posterior. (Dewey, 1958, p. 111)

O naturalismo deweyano tem como categoria central a concepção de acontecimento como oposição à categoria de ser fixo e imutável que pressupõe um sujeito passivo e expectador diante do mundo. Neste sentido, vale a pena entender a formulação deweyana de acontecimento como possibilidade de o pensamento exercer a função de intervenção e direção do processo:

Em primeiro lugar se admite que alguns acontecimentos naturais são finais, quer sejam gozados, quer detestados; são acontecimentos que ocorrem sem que se tenha controle sobre eles, prescindindo da escollha reflexiva e da arte, que só casualmente ocorrem. Em segundo lugar, implica que os acontecimentos, sendo acontecimentos, e não substâncias rígidas e macicas, estão sempre em marcha e, portanto, como tais inacabados, incompletos e indeterminados. Consequientemente possuem a possibilidade de serem pilotados e governados de forma que os fins podem ser satisfação e não simplesmente términos, conclusões fechamentos. A suspensão, dúvida, hipóteses, experimento, com suas alternativas, são expoentes destas fases da natureza. Em terceiro lugar, a regulação de processos em marcha e incompletos, em busca de consequiências escolhidas, implica que existem ordens de seqüência e coexistências envolvidas; estas ordens ou relações, quando clarificadas, são meios intelectuais que nos capacitam para usar os acontecimentos como meios concretos de dirigir o curso das coisas para prever conclusões. (Dewey, 1958, p. 159)

O conceito de natureza como acontecimento em termos evolutivos, permite a Dewey esclarecer o papel ativo do pensamento ou conhecimento na condução da experiência existencial. Neste sentido, o autor reconhece sua filosofia como pragmatismo instrumentalista que destaca o papel do pensamento problematizador, investigativo, experimentador como base para produzir e verificar significados por meio da ação, destacando esta relação como a natureza do conhecimento:

Na versão lógica do pragmatismo denominada instrumentalismo, ação ou prática desempenha, realmente, um papel fundamental. Mas ele não diz respeito à natureza das consequiências, mas à natureza do conhecimento. (...) instrumentalismo significa uma teoria comportamental do pensamento e conhecimento. Significa que o conhecimento é literalmente alguma coisa que fazemos; que a análise é finalmente física e ativa, que o significado na sua qualidade lógica são pontos de vista, atitudes e métodos de comportamento sobre fatos, e que a experimentação ativa é essenciall para a verificação. Colocando de outra forma, considera-se que o pensamento não significa algum estado transcendental ou ato introduzido subitamente dentro de uma cena natuiral prévia, mas que as operações do conhecimento são respostas naturais do organismo, que constitui conhecimento em virtude da situação de dúvida na qual ele surge e em viritude do uso da investigação, reconstrução e controle sob o qual é colocado. (Dewey, 1953, p. 331-332)

Reunindo o exposto nestes dois longos excetos antecedentes, devemos entender que o papel da filosofia não pode mais ficar circunscrito a uma atividade do pensamento 
num estado transcendental ou metafísico. A filosofia é uma atividade de um organismo em um meio. Situações problemáticas levar o organismo a investigar e reconstruir os conhecimentos em vista ao seu controle da própria situação tendo em vista sua sobrevivência. Como estamos analisando, um campo de problemática da filosofia é acerca das dúvidas sobre o próprio conhecimento ou sobre o pensar, não podendo esta questão desvincular-se do contexto vivencial:" "O negócio da filosofia, na lógica ou teoria do conhecimento, não é fornecer uma explicação rival do ambiente natural, mas analisar e relatar como e em que efeitos as investigações realmente continuam, geneticamente e funcionalmente, em seu contexto vivencial" (Dewey, 1939, p. 533).

Neste sentido, Dewey desfere sua crítica à epistemologia: "Eu tenho sustentado que os defeitos relativos a ambas as epistemologias idealistas e realistas resulltam de sua incapacidade de definir o conhecimento no contexto de situações problemáticas [...] (Dewey, 1939, p. 560)

Dewey defende a necessidade e a possibilidade da lógica ser definida como a "inquirição dentro da inquirrição", como sendo a sua versão daquilo que tem se chamado epistemologia ou teoria da inquirição:

Eu havia suposto que há na existência uma vasta multidão de inquirições, investigações de quantidades e qualidades, de eventos passados, de coisas que coexistem, ou temas matemáticos, de eventos sociais, etc., que constituem o material de todas as ciências, e que a empresa da lógica é investigar as diferentes inquirições, em conexão com as conclusões a que chegam de forma a enquadrar a teoria geral da inquirição fundada e justifíicada por aquilo que acontece nestes casos particulares. (Dewey, 1939, p. 561)

O autor indica que a investigação pode se voltar sobre o próprio processo do conlhecimento. Assim, destaca-se a necessidade de compreender este processo. Considerando a investigação da investigação poderia dizer que esta fórmula pode ser entendida também como o conhecimento do conhecimento. Assim, Dewey deu uma nova função para a lógica como investigação da investigação de forma a elaborar uma teoria geral da inquirição baseado na concepção de pensamento reflexivo que estabelece significados capazes de regular a ação. Diz Dewey:

A parte do conhecimento, as coisas da nossa experiência comum são fragmentárias, casuais, regulamentadas por fỉm, cheias de frustração e barreiras. Mas voltamos do pensamento abstrato à experiência que temos deles o qual the acrescentou significado e aumentou o poder de regular as nossas relações com eles. Conhecimento reflexivo é o único meio de regulação. Seu valor como instirumental é úinico. É congenial ao nosso idioma chamar as conclusões reflexivas de métodos competentes pelo nome da ciência. Mas a ciência assim concebida não é o final. A últimna coisa é a valorização e uso das coisas da experiência direta. Estas são conhecidas na medida em que os seus constituintes e sua forma são resultado da ciência. Mas eles também são mais do que ciência. Eles são objetos naturais sentidas nas relações e continuidades que são resumidas em formas individuais ricas e definitivas. (Dewey, 1939, p. 218-219)

O autor levanta um problema em relação à forma como a epistemologia trata o "objeto do conhecimento", diferenciando-o de uma análise lógica-filosófica. No argumento deweyano, o material experienciado na inquirição passa por uma série de fases temporais cada uma com status próprio: a fase inicial, que ele chama de matéria de discussão (subject-matter) é a de uma situação não cognitiva, mas que a problemática é sentida e a partir da qual o conhecimento se desenvolve; a segunda fase, denominada de objeto (object), é intermediária e o material (assunto, conteúdo) está condicionado à inquirição sendo provisório, condicional, sujeito a complementação; a terceira fase, chamada de conteúdo (contents) é terminal em que o conhecimento é adquirido pelo 
processo da inquirição. Retornaremos a estas fases do pensamento reflexivo na sequência de nosso estudo.

A análise lógica da innquirição mostra como uma fase fornece as propriedades que são refinadas pela reflexão na fase posterior. Por isso, se faz necessária a distinção entre o objeto de conhecimento - investigação da investigação ou conhecimento do conhecimento - e os objetos particulares em cada caso de investigação, como problema da teoria do conhecimento. Desta forma, teoria lógica do conhecimento é formada em termos de objeto do conhecimento que se verifica a partir da análise crítica de casos reais de conlhecimento de acordo com o padrão estabelecido pela inquirição experimental. Por decorrência, podemos dizer que a lógica é a crítica da investigação ou crítica do conlhecimento.

Assim entendido, Dewey desfere sua crítica às teorias epistemológicas que formulam suas teorias do conhecimento apenas na análise das características próprias do seu objeto e reivindicam solucionar a sua natureza analisando a mente, a consciência, estados mentais etc. Ao admitir o reino separado da consciência ou da mente não consegue mais sair dele para um mundo que lhe é externo. Assim, diz $\mathbb{D}$ ewey: "A discussão epistemológica, [...] está definitivamente marcado por confusões quanto à origem desta fonte". (Dewey, 1939, p. 566). Ele continua sua crítica: "[...] jogando fora água do banho epistemológico, eu não tinha intenção de também jogar fora o bebê" (Dewey, 1939, p. 566).

Reforçando o papel da lógica na sua teoria conhecimento a partir do método experimental de pensamento reflexivo, Dewey deixa claro que prefere chamar de inquiriç̧ão lógica ao invés de inquirição epistemológica:

[...] o método é supremo na solução direta de todos os problemas de primeira imão na experiência, de modo que a investigação epistemológica - inquiirição lógica na minha terminologia - tem apenas a empresa de apontar os aspectos característicos do método que é supremo nestas investigações de primeira măo. (Dewey, 1939, p. 582, itálico do autor)

A inquirição lógico-filosófica do conhecimento nos permite investigar as leis da experiência para melhor conduzi-la. A lógica da investigação depende da compreensão da própria natureza. Ela tem a função de reintegrar a atividade do homem na estrutura geral da evolução universal. Desta forma, Dewey busca compreender o processo orgânico de origem do conhecimento, baseado no modelo biológico de adaptação do homem ao meio permitindo a continuidade da vida:

[...] a interação do organismo e meio, levando a certa adaptação que assegura a utilização deste último, é o fato primeiro, a categoria fundamental. O conhecimento está relegado a uma posição derivada, secundária por origem, implicada no processo em virtude do qual se mantém e se desenvolve a vida. (DEWEY, 1954, p.87)

O critério para julgar o pensamento / conhecimento como bom ou válido é o ajustamento que consegue realizar entre o organismo e o meio: "[...] cada distinto órgão, estruttura ou formação, todo grupo de células ou elementos (...) como um instrumento de ajustamento ou adaptação a uma particular situação ambiental." (DEWEY, 1953, p. 15) Daí a importância da consequiência - adaptação e continuidade da vida ou não constituir o critério lógico que avaliza o valor do conhecimento como verdadeiro.

As bases da análise lógica do conhecimento são expostas por Dewey na sua matriz naturalista da experiência, composta de três níveis, como veremos.

O primeiro nível é chamado de físico-químico. Refere-se à existência dos seres inanimados onde o processo de equilíbrio de energia físico-química é denominado de saturação.

O segundo nível, Dewey intitulou de psico-físico. Este nível comporta os organismos com vida. Neste nível, o organismo e o meio se relacionam pelo princípio de 
interação e continuidade na troca das condições necessárias para a sobrevivência. Dewey faz um esclarecimento importante neste nível para evitar o dualismo entre organismo e meio: "[...] um organismo não vive em um meio, vive em virtude de um meio circundante" (DEWEY, 1960, p. 25, itálico do autor). Organismo e meio estão em constante processo de equilíbrio; eles atuam e se modificam reciprocamente.

O organismo busca a conservação. O princípio da vida segue um padrão: o organismo tem necessidades, condição em que há desequilíbrio de energia. Para reequilibrar o organismo reage, empreendendo esforço de busca da energia necessária para continuar sua atividade vital. O processo se fecha quando há satisfação da necessidade, produzindo equilíbrio do organismo e de alguma maneira o processo continua em relação ao meio. Do processo de conservação dos organismos vivos resulta modificação e acréscimo em si. Este processo é responsável pela evolução orgânica: o organismo adquire qualidades e eficiências.

A primeira qualidade é a organização que representa a unidade funcional do organismo. A segunda é a sensibilidade, que visa perpetuar o organismo. A sensibilidade pode ser de dois tipos: as que se dão em atividades de contato direto chamadas de realizadoras ou consumadoras e são próprias do universo vegetal. No segundo, tipo temos a sensibilidade dos organismos com capacidade de movimento próprias do universo animal. Estes organismos superiores são dotados de receptores à distância como a vista, ouvido e em menor grau o olfato e de órgãos de locomoção que lhes permitem conectar-se tanto com o próximo quanto com o remoto. Quando as atividades são de interação à distância ou indiretas, elas são chamadas de preparatória ou antecipativa. Assim, os animais desenvolvem atividades de contato direto e atividades de interação à distância ou indiretas. Consequentemente, o comportamento tem um caráter de seqüencialidade, com uma ordem definida de atividades iniciais, intermediárias e finais. A diferenciação de atividades preparatórias e consumatórias resulta numa "tensão" porque elas não se encontram de acordo. A sensibilidade, enquanto uma capacidade do organismo, é atualizada neste processo como sentido. Ao criar suscetibilidade para o útil ou o nocivo no ambiente, cria-se uma premunição, motivos para eventuais conseqüências na vida. A consumação de uma atividade traz acumulação, integração e conservação de sentidos. Nesse processo, o sentido pode receber e sustentar distinções sem fim através da variação entre si num processo de multiplicação. Do mesmo processo, em termos fisiológicos, é gerada a diferenciação dos órgãos dos sentidos, extra-ceptores e intra-ceptores.

A capacidade de acumular sentidos foi se desenvolvendo em determinados organismos criando e complexificando órgãos interiores (articulados com os exteriores). As atividades psico-físicas ganham novas estruturas, na medida em que as interações ocorrem de forma compartilhada com os outros membros da espécie. Desta maneira, as qualidades dos sentidos passam a ser diferenciadas e significadas com o uso da linguagem, dando origem à mente. Estamos assim, no nível mental, terceiro nível da matriz naturalista, que sofre transformações e acréscimos gerando a matriz cultural. Este nível é o que se encontra o homem no seu processo evolutivo.

Sem o uso da linguagem os sentidos são sensações de dor, prazer, calor, barulho, cheiro etc., apenas potenciais. O uso da linguagem permite discriminar e identificar essas qualidades, objetificá-las como traços característicos imediatos das coisas, dar-lhes significado. Estes significados criados em contextos experiências são acumulados pelo organismo através da linguagem. Desta forma, eles podem ser comunicados.

Para Dewey, este terceiro nível da experiência consiste "[...] primariamente de relações ativas entre um ser humano e seu ambiente natural e social." (DEWEY, 1979b, p. 301).

A experiência é da natureza, e como tal ocorre na natureza e no organismo humano. A transformação no processo experiencial ocorre tanto no organismo como no meio: 
O organismo atua sobre as coisas que o rodeiam, valendo-se de sua própria estrutura, simples ou complexa. Em sua consequiência, as mudanças que produzem nesse meio circundante reagem a sua vez sobre o organismo e sobre suas atividades. O ser vivente sofre as consequiências de seu próprio agir. Esta íntima conexão entre agir e sofrer ou padecer é o que chamamos experiência. $O$ agir ou o sofrer, desconectados um do outro, não constituem nenhum dos dois a experiência. [...] Uma coisa vem a sugerir e a significicar a outira. Temos, pois, uma experiência em um sentido vital e significativo. (DEWEY, 1958, p. 110-111)

Os sentidos são os órgãos pelos quais a criatura viva participa diretamente das ocorrências do mundo ao seu redor. A experiência é o resultado, o sinal e a recompensa da interação entre organismo e meio que, quando plenamente realizada, é uma transformação da interação em participação e comunicação.

Graças à relação entre o que é feito e o que é sofrido - em ambos os casos temos a ação orientada por significados que se reforçam ou anulam - , há na percepção um sentido imediato das coisas como compatíveis ou incompatíveis, reforçadoras ou interferentes. As consequências do ato de fazer, tal como transmitidas nos sentidos, mostram se aquilo que é feito transmite a idéia que está sendo executada ou assinala um desvio e uma ruptura. Sobre o caráter da razão na experiência, Dewey afirma: "Quando o ato de tentar ou experimentar deixa de ser cego pelo instinto ou costume, e passa a ser orientado por um objetivo e levado a efeito com medida e método, ele torna-se razoável racional" (Dewey, 1979, p. 300). Dessa forma, ele defende outro papel para a razão na experiência: "A razão deixa de ser faculdade remota e ideal, e significa todos os recursos por meio dos quais a atividade se torna fecunda em significações" (Dewey, 1979, p. 304).

A razão (pensamento, inteligência) exercendo esta função no curso da experiência faz com que esta não é seja mais empírica ou metafísica, mas experimental, ou seja, atividade prática dirigida pelo conjunto de concepções sugeridas, processadas e verificadas pelo pensamento reflexivo, constituindo conhecimentos comprovados.

A percepção dessas relações conceituais no interior da experiência deve-se à presença da reflexão no processo, condição para que ela seja acrescida do elemento conceitual, ou seja, de um significado. "[...] é o discernimento da relação entre aquilo que tentamos fazer e o que sucede em consequiência. Sem algum elemento intelectual não é possível nenhuma experiência significativa" (Dewey, 1979, p. 158). Na experiência reflexiva ou experimental que difere da experiência de erro-acerto, a observação é ampliada, as consequências antecipadas: "Analisamos para ver com justeza o que existe entre as duas coisas, de modo a ligar a causa ao efeito, a atividade e a consequiência" (Dewey, 1979b, p. 158).

Na experiência reflexiva, o objetivo do pensamento é resolver a situação de conflito que rompe a continuidade do organismo-meio em determinado contexto. Isto significa transformar a situação, introduzindo novos elementos não conhecidos anteriormente. O objeto do pensamento é uma situação de conflito que antecede e evoca - próprio pensamento. Os dados emergem da própria situação no processo de investigação. O seu objetivo é o estágio final no desenvolvimento da investigação, que culmina com uma significação verificada praticamente.

O pensamento reflexivo ou a investigação reflexiva ou a lógica da investigação, e ainda, o conhecimento do conhecimento, como vimos anteriormente, diferenciando-se de outras operações do pensamento, é caracterizado por duas fases complementares conforme concebe $\mathbb{D}$ ewey: "(1) um estado de dúvida, hesitação, perplexidade, dificuldade mental, o que origina o ato de pensar; e (2) um ato de pesquisa, procura, inquirição, para encontrar material que resolva a dúvida, assente e esclareça a perplexidade." (DEWEY, 1979, p. 22)

A função do pensamento reflexivo é resolver a situação problemática. De acordo com a concepção deweyana, a função do pensamento reflexivo é: "transformar uma situação de obscuridade, dúvida, conflito, distúrbio de algum gênero, numa situação clara, coerente, assentada, harmoniosa." (DEWEY, 1979a, p. 106, itálicos do autor). 
Pensamento reflexivo é a atividade inteligente que exige esforço consciente e voluntário que reconstrói as crenças através da investigação: "O pensamento reflexivo faz um ativo, prolongado e cuidadoso exame de toda crença ou espécie hipotética de conhecimento, exame efetuado à luz dos argumentos que a apóiam e das conclusões a que chega." (DEWEY, 1979a, p. 18, itálicos do autor). Disso decorre a definição de inquirição para Dewey: A inquirição é a transformação controlada ou dirigida de uma situação indeterminada em outra que é de tal modo determinada nas suas distinções e relações que a constituem que converte os elementos da situação original em um todo unificado. (DEWEY, 1960, p. 104, itálicos do autor)

Este modo de analisar o processo do conhecimento, como discutimos no início deste texto, é definido por Dewey como a lógica da investigação, diferenciando-se da epistemologia. O resultado de seu estudo como lógica da investigação, ou a investigação da investigação, ou investigação de como os homens pensaram ao longo da história culminou na pauta da investigação descrita da seguinte forma:

Isto é o que se refere aos aspectos gerais de uma experiência reflexiva. São eles: 1) perplexidade, confusão e dúvida, devidas ao fato de que a pessoa está envolvida em uma situação incompleta cujo caráter não ficou plenamente determinado ainda; 2) uma previsão conjetuiral - uima tentativa de interpretação dos elementos dados, atribuindo-lhes uma tendência para produzir certas conseqưências; 3) um cuildadoso exame (observação, inspeção, exploração, análise) de todas as considerações possíveis que definam e esclareçam o problema a resolver; 4) a consequente elaboração de uma tentativa de hipótese para torná-lo mais preciso e mais coerente, harmonizando-se com uma série maior de circunstâncias; 5) tomar como base a hipótese concebida, para o plano de ação aplicável ao existente estado de coisas; fazer alguma coisa para produzir o resultado previsto e por esse modo pôr em prova a hipótese. (Dewey, 1979, p. 164-165)

Assim, o pensamento tem a função instrumental e funcional no processo de inquirição da dúvida à solução ou da indeterminação à determinação da situação pela descoberta e reconstrução dos significados.

Estes significados resultantes são aprendizados que, somando-se a outras experiências, constituem o próprio "eu":

[...] o processo do viver é contínuo; tem continuidade por ser um processo permanentemente renovado de ação sobre o meio e exposição à ação dele, juntamente com a instituição de relações entre o que se faz e o que se sofre. Portanto, a experiência é necessariamente cumulativa, e seu conteúdo ganha expressividade por causa da continuidade cumulativa. $O$ mundo que experimentamos no passado se toma parte do eu que age e sofire a ação em outras experiências. Em sua ocorrência física, as coisas e eventos experienciados passam e acabam. Mas algo de seu significado e valor é preservado como parte integrante do eu. Através dos hábitos formados na interação com o mundo também habitamos o mundo. Elle se toma um lar, e o lar faz parte de nossa experiência cotidiana. (DEWEY, 2010, p. 211-212).

Por isso, Dewey fala que o valor da experiência está na continuidade, acúmulo, crescimento que permite para novas experiências: "1) A experiência é, primariamente, uıma ação ativo-passiva; não é, primariamente, cognitiva. Mas 2) a medida e valor de uma experiência reside na percepção das relações de continuidades a que nos conduz." (DEWEY, 1979, p. 153, itálicos do autor) A experiência está regida pelos princípios de continuidade e interação. A continuidade corresponde à dimensão longitudinal da experiência, o que nos permite compreendê-la sob as categorias da mudança e conseqüentemente da historicidade. 
Neste caso, cada experiência influencia as condições objetivas sobre as quais as novas experiências acontecem. Pensemos como certas experiências da criança como engatinhar, caminhhar, falar etc. influenciam as experiências subseqüentes.

A interação compreende a dimensão de lateralidade da experiência, abarcando o contexto cultural e social. Cada experiência envolve contato social e comunicação. Ela não é algo que ocorre exclusivamente dentro de uma pessoa, mas envolve a interação com a comunidade:

O trabalho de conversão da fase orgânica e física do comportamento associado numa comunidade de ação saturada e regulada pelos interesses mútuos nos significados partilhados, consequeências que são traduzidas em idéias e objetos desejados por meio dos símbolos, não ocorre toda de uma vez nem completamente. A cada momento, ela apresenta problemas mais do que uma aquisição assentada. Nós nascemos seres orgânicos associados com os outros, mas nós não nascemos membros de uma comunidade. A criança tem que ser trazida através das tiradições, perspectivas e interesses que caracterizam a comunidade por meio da educação: por uma ininterrupta instrução e por aprender em conexão com o fenômeno da associação aberta. Tudo o que é distintivamente humano é aprendido, não é inato (native), mesmo que não seja possivel aprender sem estruturas inatas que diferenciam o homem de ouitros animais. Aprender na forma humana e no efeito humano não é somente adquirir habilidades acrescentadas por meio do refinamento de capacidades originais. Aprender a ser humano é desenvolver através do dar-e-receber da comunicação um senso efetivo de ser um membro distintivamente individual de uma comunidade; alguém que entende e aprecia suas crenças, desejos e métodos, e que contribui para converter as forças orgânicas em recursos e valores humanos. Mas a tradução nunca termina. O Velho Adão, o elemento não regenerado na natureza humana persiste. (DEWEY, 1991, p. 153-154.

A experiência é o processo do fazer-se humano na interação com a comunidade. Neste processo é fundamental o aprender a ser humano por meio da educação. Instrução e aprendizagem são processos ininterruptos e necessários para viver como membro de uma comunidade. Nesta dinâmica a comunidade também se renova, em contínuo devir tendo como sua principal característica o fim aberto - "open end".

Desta discussão resulta que sem a conceituação, como possibilidade de acumular significados e inter-relacioná-los a experiência perderia completamente sua possibilidade de crescer, ampliar, ser transmitida e, portanto, de ser educativa. Por sua vez, a educação envolve necessariamente o trabalho intelectual de reconstruir os significados da experiência:

[...j em toda fase de desenvolvimento, cada lição, para ser educativa, deveria conduzir a uma certa dose de conceptualização de impressões e idéias. Sem essa conceptualização ou intelectualização, nada se ganha que possa contribuiir para uma melhor compreensão de novas experiências. (...) tall intelectualização é o depósito de uma idéla, deffinida e geral a um tempo. Educação, em seu aspecto intelectual, e obtenção de uma idéia do que é experimentado são expressões sinônimas. (Dewey, 1979a, p. 155/6, itálicos do autor)

O autor estabelece intima relação entre a experiência investigativa ou reflexiva e a educação. Por isso, não faz sentidos uma educação voltada para o acúmulo de conhecimentos que não se conectam com a experiência no sentido exposto, ou seja, que envolve uma comunidade. Isto equivale a dizer que uma educação centrada no paradigma transmissor de conhecimentos não cria a comunidade e inibe as capacidades das pessoas de se tornarem membro da comunidade.

Sua análise destaca também os impedimentos para o crescimento da experiência que são a rotina, os procedimentos caprichosos, os costumes rígidos ou o autoritarismo, comportamentos que impedem a reflexão e a livre comunicação da experiência. 
A experiência, como analisamos, não se restringe ao campo cognitivo, formando a mente e ampliando continuamente o arcabouço de conhecimentos. O princípio da experiência é o crescimento que está articulado com outras esferas como a ética e a política. Experiência é crescimento, nesta perspectiva: "O crescimento, o desenvolvimento em si mesmo, é o único 'fim' moral" (Dewey, 1959a, p. 177). Daí a sua máxima moral: "O mau homem é o que está começando a arruinar-se, que está se tornando menos e menos bom, não obstante o quanto bom tenha sido. 0 bom homem é o que está se tornando melhor, pouco importando o quanto indigno tenha sido." (Dewey, 1959a, p. 176). O tornar-se "menos bom" ou arruinar-se é perder a capacidade de aprender pensando intrínseco à experiência, e o tronar-se melhor é ampliação desta capacidade de aprender a pensar reflexivamente.

A dimensão ética e política estão interligadas à investigativa, uma vez que o processo de pensar reflexivo tem o papel orientar a ação transformadora do mundo. Neste sentido, o pensamento reflexivo carrega o pensar ético e político para o pensar as experiências das ciências, das artes e da filosofia.

À filosofia cabe o pensar os costumes ou dos hábitos arraigados na cultura. Neste sentido, o filosofar como atividade autônoma de pensamento reflexivo, tem importante tarefa: "Sua primeira incumbência é clarificar, emancipar e estender os bens inerentes às operações da experiência naturalmente originada" (DEWEY, 1958, p. 407). Por isso, ela tem amplo valor humano e libertador, na medida em que sugere direção inteligente à ação, à emoção e ao relacionamento social. Neste sentido, continua o argumento do autor:

Uma filosofia empírica é, de qualquer modo, algo como despir-se intelectualmente. Não podemos nos despojar permanentemente dos hábitos intelectuais que contraímos e vestimos quando assimilamos a cuiltura de nosso tempo e de nosso lugar. Mas o progresso inteligente da cultura exige que abandonemos alguns desses hábitos, que os inspecionemos criticamente, a fím de descobrir sua constituição e seu uso para nós. Não podemos retornar à primitiva ingenuidade. Não obstante há uma ingenuidade cultivada dos olhos, dos ouvidos e do pensamento, a qual é atingível, mas só pode ser adquirida através da disciplina de uim pensamento rigoroso. (Dewey, 1958, p. 37)

A outra tarefa da filosofia está ligada ao problema resultante das especializações como a ciência, a indústria, a política, a religião, a arte, a educação, a moral etc. que se institucionalizam ou profissionalizam, isolando-se e se petrificando em seus mundos restritos. A tarefa crítica da filosofia:

\begin{abstract}
A super-especialização e a divisão dos interesses, as ocupações e os bens criam a necessidade de um meio geral de intercomunicação, de uma crítica mútua em torno da tradução de uma região ilhada da experiência à outra. Assim, como um órgão de crítica, a filosofia resulta, com efeito, uim mensageiro, um oficial de conexão, fazendo reciprocamente inteligíveis as vozes que falam línguas provincianas, e desta forma, ampliando e retificando as signifícações de que estão grávidas. (Dewey, 1958, p. 410).
\end{abstract}

A tarefa crítica da filosofia se amplia com a tarefa reconstrutiva das significações tornando possível a comunicação neste universo de especialidades dando inteligibilidade para a experiência. Esta tarefa resgata a função e o valor da filosofia no contexto da cultura altamente complexa. Ela se coloca como um vetor para a autonomia no exercício da liberdade de pensar, falar e agir. Impedir a atividade filosófica nas escolas é atentar contra a dignidade do homem com ser pensante.

Como mencionamos no início deste texto, Dewey estabelece as bases de sua filosofia a partir do que ele propõe como base do pensar, ou seja, a lógica. Desta forma ele toma posição crítica diante da epistemologia entendida como as filosofias dualistas 
que isolam o sujeito conhecedor do objeto conhecido. Podemos identificar alguns pontos que ele elege para contrapor sua maneira de pensar o conhecimento.

Um primeiro aspecto, a epistemologia toma a realidade como ser fixo, um objeto distinto a ser conhecido por um sujeito soberano. A esta visão ele contrapõe a realidade como acontecimento, natureza e experiência, marcado pela contingência e mudança.

A epistemologia pressupõe o conhecimento como verdades absolutas, enquanto que na versão lógica, o conhecimento é um instrumento para conduzir as experiências, reconstruindo-as, ampliando-as.

A epistemologia cria o dualismo teoria-prática. Na filosofia da experiência, o processo começa na situlação situações problemáticas que devem ser transformadas pela investigação, modificando o indivíduo e o meio.

O sujeito do conhecimento na epistemologia é um expectador da realidade que lhe fornece certezas, enquanto que na perspectiva lógica, o sujeito age e transforma a realidade, consistindo um processo ativo de adaptação.

A epistemologia gerou um saber que se transforma em costume e serve à manutenção dos poderes nas mãos de quem dirige. A lógica da investigação, a reflexão das situações problemáticas implica um processo comunicacional democrático, uma vez que a experiência é comum, realizando-se na comunidade.

Em termos educacionais, a epistemologia se sustenta por uma educação como transmissão do conhecimento. Contrapondo-se a esta perspectiva, Dewey vê a educação como formação do hábito de pensar reflexivo como capacidade de reconstrução contínua das experiências. Neste sentido, destaca-se a atividade filosófica como pensamento reflexivo sobre as crenças clarificando conceitos, e reconstruindo os significados como forma de tornar a experiência comunicável nos mais diversos campos. Por conseguinte, o pensar reflexivo é também pensar ética e politicamente a experiência na comunidade democrática.

\section{Referências}

DEWEY, John. A arte como experiência. Trad. Vera Ribeiro. São Paullo: Martins Fontes, 2010 .

Como pensamos como se relaciona o pensamento reflexivo com o processo educativo: uma reexposição.Tradução: Haydée Camargo Campos. 4a ed. São Paulo: Nacional, 1979a. Atualidades pedagógicas; vol. 2. 292 p.

- Democracia e educação. Tradução: Godofredo Rangel e Anísio Teixeira. São Paulo: Nacional, 1979b. Atualidades pedagógicas; vol. 21. 416p.

Essays in experimental logic. New York: Dover publications, 1953.444p.

Experience and nature. New York: Dover Publications, Inc., 1958. 443p.

Experience, knowledge and value. In: Schilpp, Paul A. (Editor) The Philosophy of John Dewey, Chicago: Northwestern University, 1939. p. 49-73.

Logic. The theory of inquiry. New York: Henry Hold and Company, 1960. 546p.

Reconstrução em filosofia. Tradução: Antônio Pinto de Carvalho. São Paulo: Nacional. 1959a.

Reconstruction in philosophy. New York: The New American Library, 1954.

The public and its problems. 12a. ed. Ohio: Ohio University Press, 1991. 236 p.

The quest for certainty: a study of the relation of knowledge and action. 12 ed., New York: Minton, Balch \& Company, 1929. 318 p. 
JAPIASSU, Hilton. Introdução ao pensamento epistemológico. 7a. Ed. Rio de Janeiro: F. Alves, 1992.

RATNER, Joseph. Dewey's conception of philosophy. In: Schilpp, Paul A. (Editor) The Philosophy of Jolnn Dewey, Chicago: Northwestern University, 1939. p. 49-73.

RUNES, Dagobert D. The Dictionary of Philosophy. London: Vision Press / Peter Owen, 1951 .

Doutor em Filosofia da Educação (USP, 2008) Professor adjunto do Departamento de Educação da UEL e do Mestrado em Educação/UEL E-mail: murarodinm@gmail.com 